Vol. 1 No. 1, Feb 2021, hlm. 39 - 44

DOI: https://doi.org/10.33330/.v1i1.1045

Available online at https://jurnal.stmikroyal.ac.id/index.php/jutsi

\title{
RANCANG BANGUN LOCAL CLOUD SERVER DENGAN NEXTCLOUD PADA CENTOS 7 DI SRH TRAINING CENTER
}

\author{
Ifvan Limalasa Mayendra ${ }^{1}$, Herman Saputra ${ }^{2^{*}}$, Uswatun Hasanah ${ }^{3}$ \\ ${ }^{1}$ Mahasiswa Prodi Sistem Komputer, STMIK Royal \\ ${ }^{2}$ Prodi Sistem Komputer, STMIK Royal \\ ${ }^{3}$ Prodi Sistem Informasi, STMIK Royal \\ *email: hermansaputra4@gmail.com
}

\begin{abstract}
The file becomes an important thing in any case. Especially in the world of education which is something that can't be avoided that students must be able to create and save files correctly, both assignments and reports. Files stored on a computer do not guarantee that the data will be forever stored, because every month a computer maintenance must be held in a computer laboratory. Local cloud server technology with Nextcloud that uses the CentOs 7 operating system is very suitable to be applied in the SRH Training Center laboratory as a means of storing files and managing files in a Local Area Network. In this study the local cloud server was built with apache web server and mysql database and also with several packages supporting the Nextcloud application. With the construction of a local cloud server system with Nextcloud, students and teaching staff can easily manage the required learning files.
\end{abstract}

Keywords: CentOs 7, Local Area Network, Local Cloud Server, Nextcloud, Web Server.

\begin{abstract}
Abstrak: File menjadi suatu hal yang penting dalam hal apapun. Apalagi di dunia pendidikan yang menjadi suatu hal yang tidak bisa dihindari bahwa siswa harus mampu membuat dan menyimpan file dengan benar, baik itu tugas maupun laporan. File yang disimpan dalam komputer tidak menjamin data akan selamanya tersimpan, karena setiap bulan pasti diadakan maintenance komputer yang ada di laboratorium komputer. Teknologi local cloud server dengan Nextcloud yang menggunakan sistem operasi CentOs 7 sangat cocok diterapkan dalam laboratorium SRH Training Center sebagai sarana penyimpanan file dan memanajemen file dalam satu jaringan Local Area Network. Pada penelitian ini local cloud server dibangun dengan web server apache dan database mysql dan juga dengan beberapa paket pendukung aplikasi Nextcloud. Dengan dibangunnya sistem local cloud server dengan Nextcloud, maka siswa-siswi dan tenaga pengajar dapat mudah dalam memanejemen file pembelajaran yang dibutuhkan.
\end{abstract}

Kata Kunci: CentOs 7, Local Area Network, Local Cloud Server, Nextcloud, Web Server.

\section{PENDAHULUAN}

Pesatnya perkembangan teknologi komputer memudahkan manusia dalam menyelesaikan pekerjaan secara mudah. Salah satu contoh adalah teknologi Cloud server yang sangat membantu dalam sistem penyimpanan file atau data. Cloud server adalah sebuah arsitektur IT dimana sumber daya komputasi tersedia sebagai layanan 
Vol. 1 No. 1, Feb 2021, hlm. 39 - 44

DOI: https://doi.org/10.33330/.v1i1.1045

Available online at https://jurnal.stmikroyal.ac.id/index.php/jutsi

yang dapat diakses melalui internet[1], [2]. Salah satu model cloud server adalah private cloud. Private cloud adalah layanan yang disediakan oleh cloud computing yang dioperasikan hanya untuk sebuah organisasi/perusahaan tertentu.[3]-[5]. Tujuan utama penyeberan private cloud adalah tidak menjual kapasitas melalui jaringan internet dengan publicly accessible interface tetapi memberikan pengguna lokal fleksibelitas dan kecepatan dari infrastruktur lokal. Maka dari itu private cloud dapat disebut dengan sistem local cloud server yang dapat memanejemen data.

Dalam dunia pendidikan yang teknologi local cloud server ini memberikan banyak manfaat terutama bagi dunia pendidikan yang pada hakikatnya memiliki kegiatan operasional sehari-hari dengan keberadaan dokumen-dokumen digital. Salah satu lembaga pendidikan tersebut adalah Lembaga Kursus Pelatihan SRH Training Center. Berlokasi di jalan pulau rakyat pekan kecamatan pulau rakyat kabupaten asahan. LKP tersebut berdiri pada tahun 2019 dan dikelola langsung oleh bapak Faisal Azmi. Dengan terbatasnya perangkat penyimpanan yang dimiliki siswa-siswi LKP SRH Training Center, maka akan memungkinkan penempatan dokumen tersebut menjadi tidak beraturan dan tersebar di berbagai perangkat penyimpanan yang bukan milik perseorangan siswa tersebut.

Untuk mengatasi masalah dalam hal penyimpanan dan menajemen file yang dibuat oleh siswa, solusi yang diambil adalah dengan membangun local cloud server pada sebuah komputer yang akan dijadikan sebuah server local yang bersifat private dengan menggunakan sistem operasi CentOs 7. Sehingga siswa tidak perlu khawatir data mereka akan hilang saat disimpan pada laboratorium komputer SRH Training Center.

\section{METODE}

Metode penelitian yang digunakan yaitu mengumpulkan data dengan mencari gambaran melalui sebuah sistem berskala kecil atau sederhana (model) dimana didalam model tersebut akan dilakukan manipulasi atau kontrol untuk melihat pengaruhnya.

\section{HASIL DAN PEMBAHASAN}

Berikut ini adalah implementasi dari rancang bangun local cloud server dengan nextcloud pada centos 7 di srh training center:

\section{Login}

Setelah melakukan konfigurasi nextcloud, maka pada browser ketikkan alamat domain yaitu dns.cloud.id. Pembuatan akun admin berdasarkan konfigurasi yang sudah dilakukan sebelumnya pada konfigurasi mariadb. 
Vol. 1 No. 1, Feb 2021, hlm. 39 - 44

DOI: https://doi.org/10.33330/.v1i1.1045

Available online at https://jurnal.stmikroyal.ac.id/index.php/jutsi

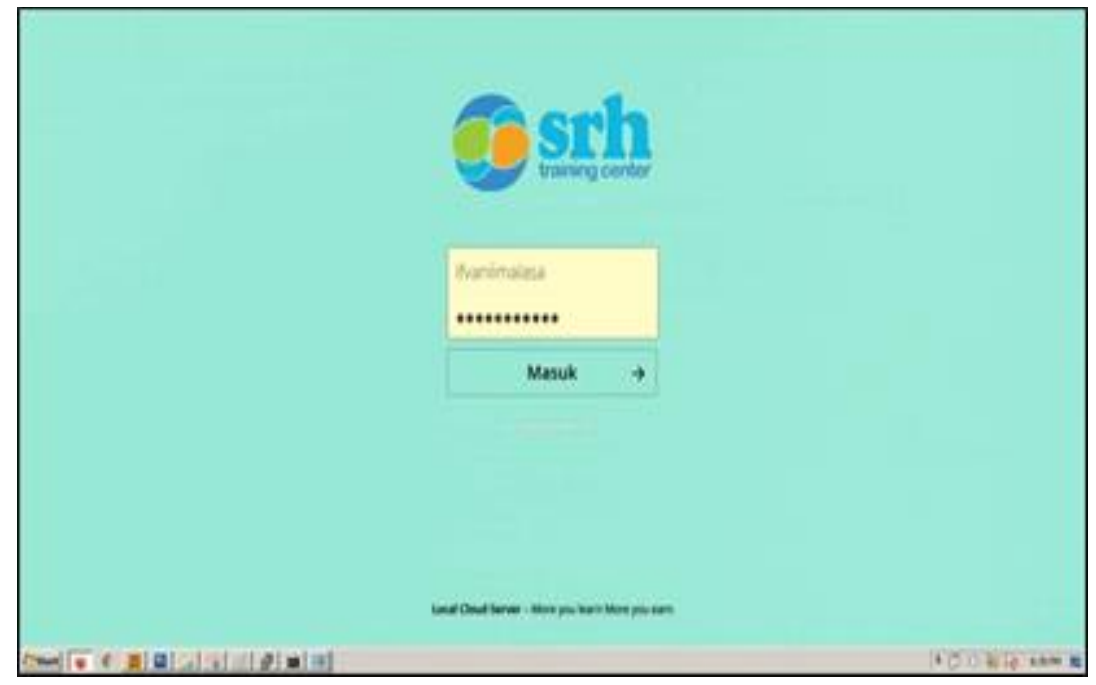

Gambar 1. Tampilan Login

\section{Menu Utama}

Gambar diatas merupakan tampilan awal dari sistem nextcloud default. Dalam penerapannya, sistem local cloud server digunakan pada SRH Training Center sehingga tampilannya berbeda dapat dilihat pada gambar pada gambar 2 .

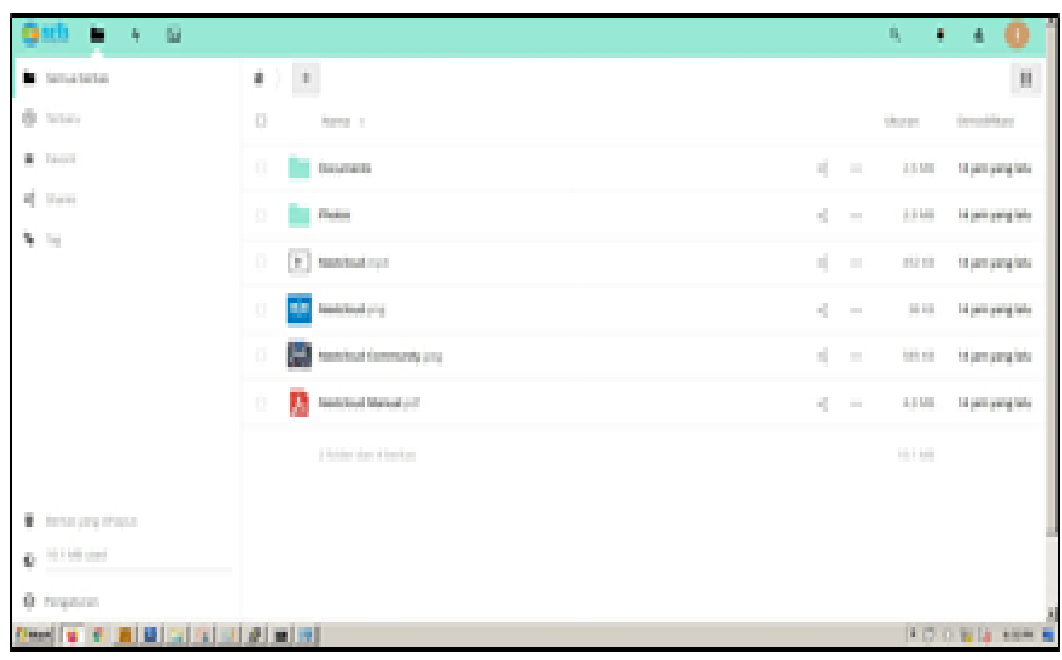

Gambar 2. Tampilan Menu Utama

\section{Pembuatan Menu User}

Setelah pengujian login admin maka pengujian berikutnya adalah proses pembuatan akun cloud server untuk instruktur dan siswa yang digunakan untuk menyimpan file pembelajaran pada SRH Training Center. 
Vol. 1 No. 1, Feb 2021, hlm. 39 - 44

DOI: https://doi.org/10.33330/.v1i1.1045

Available online at https://jurnal.stmikroyal.ac.id/index.php/jutsi

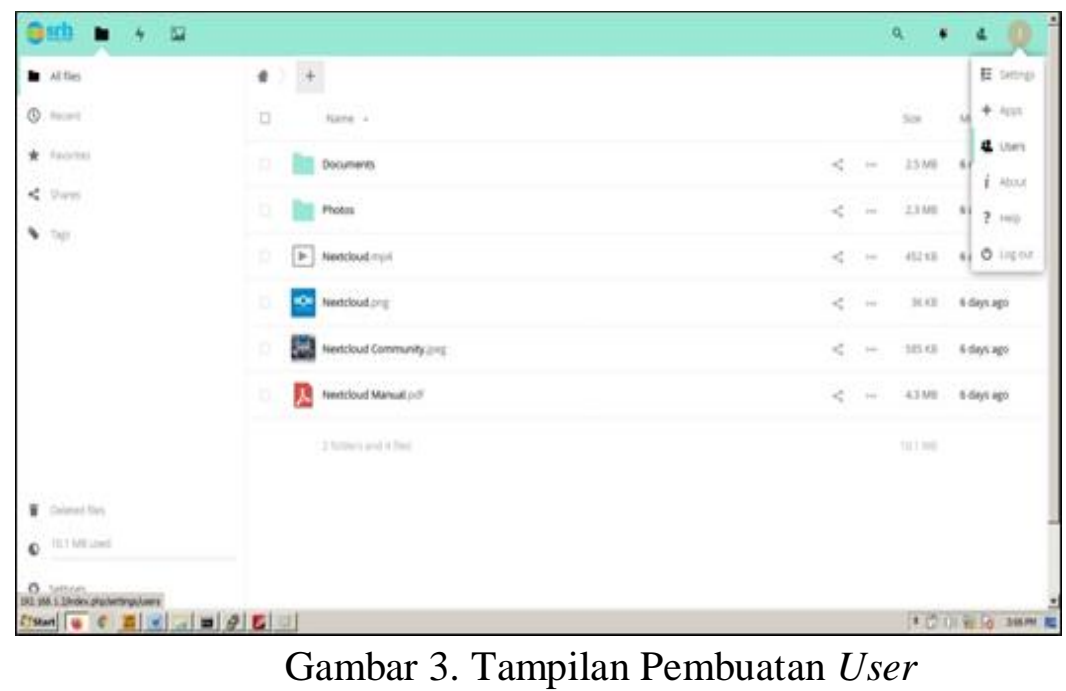

Untuk menu pembuatan user berada pada kanan atas dashboard admin nextcloud. Pilih menu user pada logo admin. Tahap selanjutnya adalah membuat user baru yaitu instruktur dan siswa dengan mengisi username, display name, password, email, groups dan quota penyimpanan setiap user dengan kapasitas 1 Giga Byte. Setelah itu muncul tampilan seperti pada gambar 4.

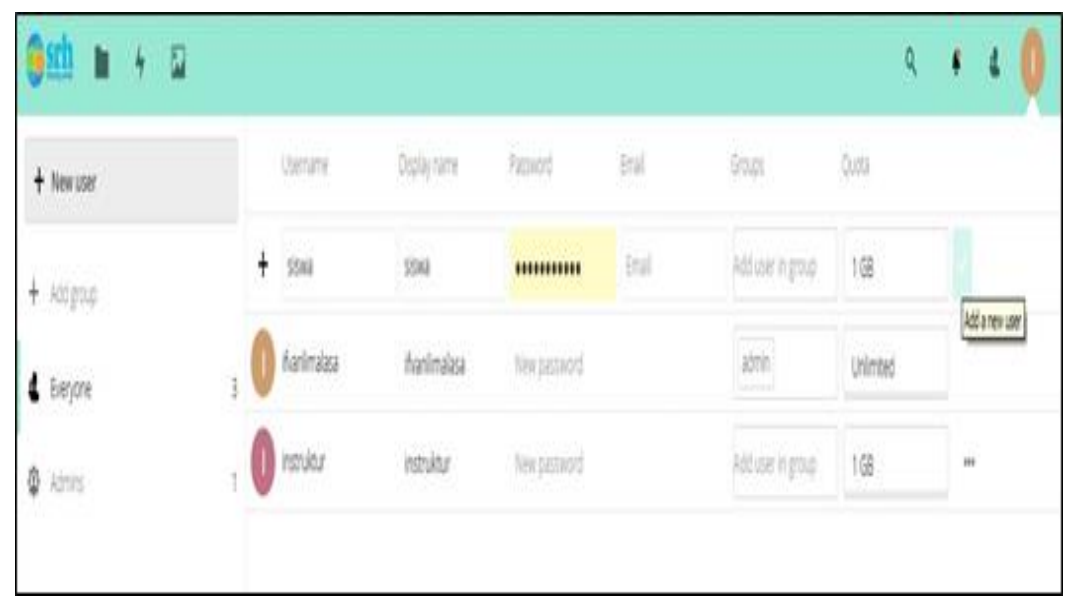

Gambar 4. Tampilan Pembuatan User Instruktur dan Siswa

\section{Menu Upload}

Pengujian ini dilakukan agar mengetahui sistem dapat bekerja dengan baik atau tidak. Karena konsep dari local cloud server adalah melakukan upload file ke server yang akan di backup. Login sebagai instruktur dengan username dan password yang telah dibuat admin. Jika berhasil tampilkan halaman upload, maka tampilannya dapat dilihat pada gambar 5 . 
Vol. 1 No. 1, Feb 2021, hlm. 39 - 44

DOI: https://doi.org/10.33330/.v1i1.1045

Available online at https://jurnal.stmikroyal.ac.id/index.php/jutsi

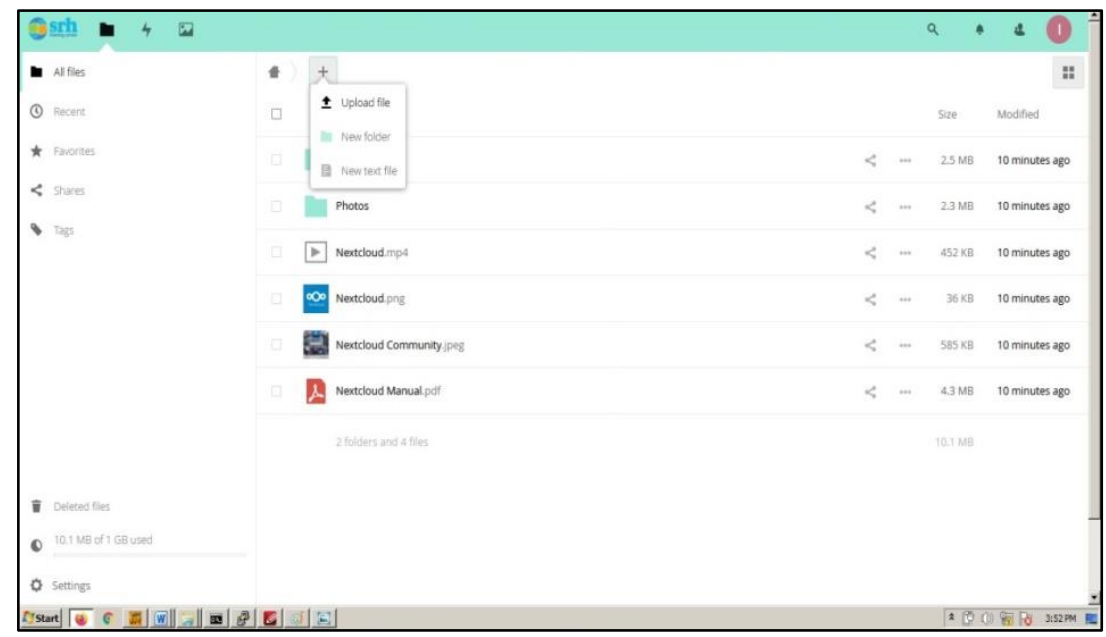

Gambar 5. Tampilan Upload

\section{Menu Download Modul}

Pengujian ini dilakukan untuk mengunduh file yang ada pada sistem nextcloud atau yang sudah di upload. Login sebagai siswa untuk mengunduh modul yang di upload instruktur. Dengan cara pilih modul yang ingin diunduh kemudian pilih tombol action dan download.

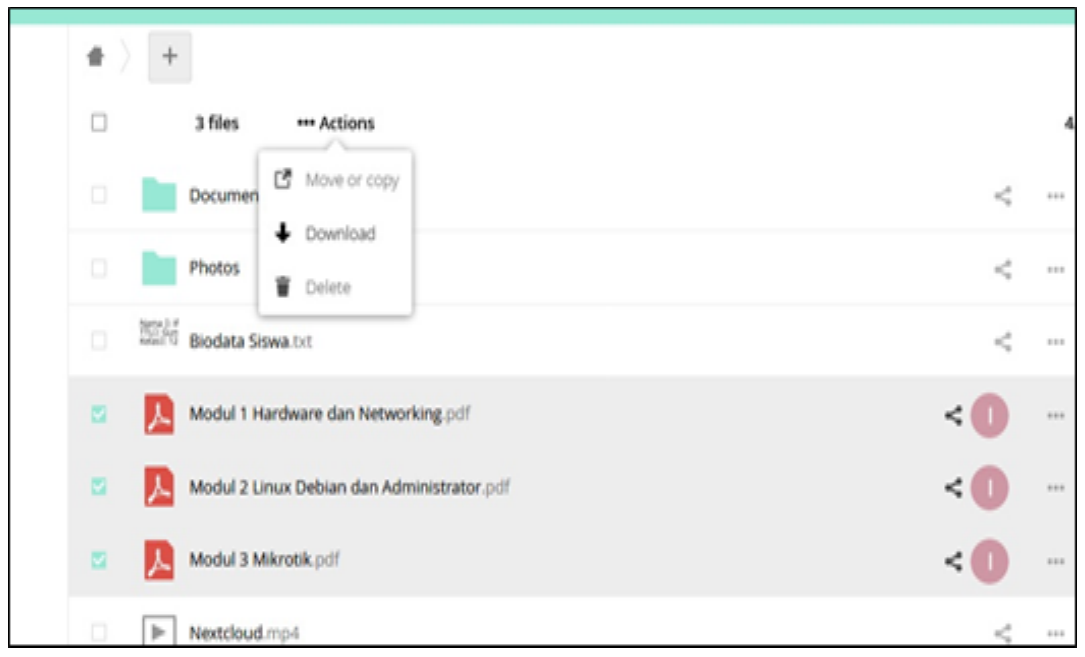

Gambar 6. Tampilan Download

\section{Tampilan Share File}

Pengujian ini dilakukan untuk membagikan file yang ada pada sistem. Proses dari instrukur ke siswa untuk membagikan modul pembelajaran ataupun siswa ke instruktur untuk membagikan hasil belajar.

Untuk membagikan file pilih simbol share dan masukkan nama user yang akan menerima file tersebut. Disini menggunakan contoh file nextcloud.png dari admin ke siswa. Dengan tampilan seperti dibawah ini. 
Vol. 1 No. 1, Feb 2021, hlm. 39 - 44

DOI: https://doi.org/10.33330/.v1i1.1045

Available online at https://jurnal.stmikroyal.ac.id/index.php/jutsi

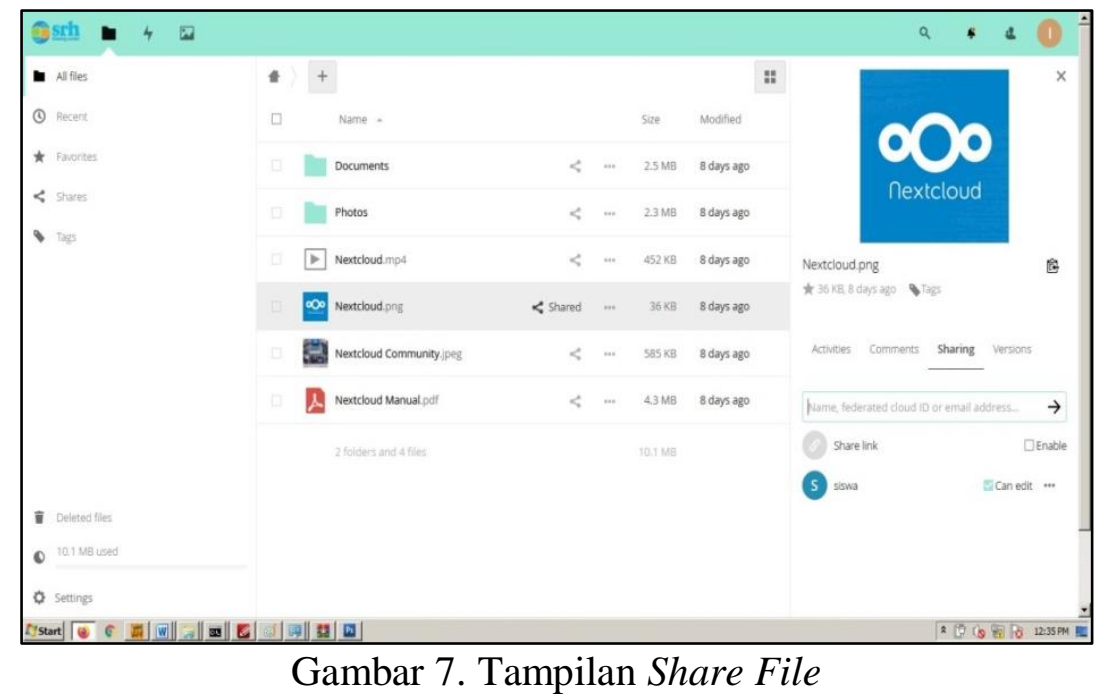

\section{SIMPULAN}

Adapun simpulan yang dapat diambil adalah sistem local cloud server dengan centos 7 dapat diterapkan untuk manajemen file pada lembaga pendidikan seperti SRH training center sehingga memudahkan proses pembelajaran tanpa khawatir terhadap kehilangan file dan menghemat pemakaian perangkat penyimpanan.

\section{DAFTAR PUSTAKA}

[1] M. Nurohman, A. S. H, and E. Riana, "Perancangan Private Cloud Computing Pada Kementerian Perindustrian Jakarta," 2453-7850-2-Pb, vol. 4, no. 1, p. 8, 2018.

[2] M. Ibrahim and K. Kusnawi, "Analisis Dan Implementasi Owncloud Sebagai Media Penyimpanan Pada Yayasan Salman Al - Farisi Yogyakarta," Data Manaj. dan Teknol. Inf., vol. 14, no. 3, p. 32, 2013.

[3] P. Nugraha, I. Mogi, and I. Setiawan, "Implementasi Private Cloud Computing Sebagai Layanan Infrastructure As a Service (Iaas) Menggunakan Openstack," J. Ilmu Komput., vol. 8, no. 2, pp. 7-14, 2015.

[4] H. Wintolo and L. S. Dwi Paradita, "Layanan Cloud Computing Berbasis Infrastructure As a Service Menggunakan Android," Compiler, vol. 4, no. 2, pp. 11-18, 2015, doi: 10.28989/compiler.v4i2.91.

[5] W. Adiansyah and Kartini, "Membangun Jaringannirkabel ( Hotspot Area ) Dan Manajemen Hotspotdengan "Antamedia Hotspot Manager ," vol. 10, no. September, pp. 1-23, 2014. 